\title{
HERMENÊUTICA E TEORIA DO DIREITO: TRAJETÓRIA DE DOIS CAMPOS ESTRUTURANTES DO PENSAMENTO JURÍDICO NO BRASIL
}

\author{
HERMÉNEUTIQUE ET THÉORIE JURIDIQUE: L'HISTOIRE DE DEUX \\ DOMAINES FONDAMENTAUX DE LA PENSÉE JURIDIQUE AU BRÉSIL
}

\author{
${ }^{1}$ Gretha Leite Maia \\ ${ }^{2}$ Zaneir Gonçalves Teixeira
}

\section{RESUMO}

$\mathrm{O}$ artigo objetiva analisar algumas concepções em torno da relação entre a Hermenêutica jurídica e a Teoria do Direito, a partir de determinados questionamentos implicados nessa relação. Parte da constatação de que existe um movimento de centralidade da Hermenêutica no Brasil nos últimos 20 anos. Investiga como se definem, em termos de campo de pesquisa, a Teoria do Direito e a Hermenêutica, e em que medida existe uma colonização de conteúdo entre estas áreas estruturantes do pensamento jurídico. Examina os caminhos da Hermenêutica no âmbito da produção acadêmica jurídica brasileira e verifica o que confere legitimidade ao seu discurso. Analisa a proposta de uma nova Hermenêutica, que acompanha o neoconstitucionalismo e o pós-positivismo. Analisa igualmente a relação entre a Teoria do Direito, a Hermenêutica jurídica e o positivismo jurídico. Conclui posicionando-os como campos inter-relacionados, porém sem prevalências, com propostas de investigação próprias e por isso identificáveis, a que se acresce a proposta da Teoria da Decisão. Trata-se de pesquisa bibliográfica e analítica.

Palavras-chave: Hermenêutica, Teoria do direito, Objeto, Pesquisa

\section{RÉSUMÉ}

Cette étude analyse certaines conceptions sur la relation entre l'herméneutique juridique et la théorie du droit, de certaines questions impliquées dans cette relation. Il affirme qu'il ya un mouvement de centralité de l'herméneutique au Brésil au cours des 20 dernières années. Étudie comment sont définis les objets de recherche de la théorie juridique et de 1 herméneutique, et dans quelle mesure il ya une colonisation entre ces domaines fondamentaux de la pensée juridique. Examine lhistoire de lherméneutique au sein de la littérature académique juridique brésilien pour vèrifier ce qui donne légitimité à son discours. Examine la proposition pour une nouvelle herméneutique, accompagnant le neoconstitutionalism et post-positivisme. Il analyse également la relation entre la théorie du droit, l'herméneutique juridique et le positivisme juridique. Conclut par les positionner comme domaines interdépendants, mais sans la prévalence, avec des propositions de recherche propre et donc identifiable, à laquelle on ajoute la proposition de la théorie de la décision. La recherche est bibliographiques et analytiques.

Mots-clés: Herméneutique, Théorie du droit, Objet, Recherche

\footnotetext{
${ }^{1}$ Doutora em Direito pela Universidade Federal do Ceará - UFC, Ceará (Brasil). Professora da Faculdade de Direito da Universidade Federal do Ceará - UFC, Ceará (Brasil). E-mail: grethaleitemaia@ gmail.com

${ }^{2}$ Doutoranda do Programa de Pós-Graduação em Direito da Universidade Federal do Ceará - UFC, Ceará (Brasil). Professora do Curso de Direito da Universidade de Fortaleza - UNIFOR, Ceará (Brasil). E-mail: zaneir@ hotmail.com
} 


\section{INTRODUÇÃO}

O artigo que se segue objetiva analisar as principais concepções em torno da relação entre a Hermenêutica e a Teoria do Direito, a partir de determinados questionamentos implicados nessa relação. Parte da constatação de que existe um movimento de centralidade da Hermenêutica no Brasil nos últimos 20 anos. São sintomas desse movimento a inserção de cadeiras de Hermenêutica como obrigatórias no curso de graduação, a explosão do mercado editorial do tema Hermenêutica Jurídica e o volume de dissertações e teses que se produziram tendo esta como paradigma de investigação. Indaga-se: esse movimento de centralidade pode sugerir um ocaso da Teoria do Direito, por esvaziamento de objeto ou por colonização de conteúdo e campo de pesquisa? A Teoria do Direito se reduz ao positivismo jurídico? É preciso ultrapassar o positivismo jurídico para adotar a hermenêutica como "metodologia" do

Direito? É possível sustentar esse deslocamento da Teoria do Direito de central para periférica em razão do movimento oposto feito pela Hermenêutica? O que há de novo no discurso hermenêutico que justifique o entusiasmo inovador que invade e legitima este campo de estudos? Qual a relação existente entre o retorno triunfal da Hermenêutica e a introdução da expressão "Democrático" na fórmula "Estado de Direito", conforme dispõe a CRFB/88? Houve uma "superação" do paradigma da validade no Direito por um novo critério de aptidão do Direito para produzir efeitos (a legitimidade) ou mais um critério foi estabelecido ao lado do critério da validade de norma jurídica e legalidade da decisão judicial? Que modelos de racionalidade são superados quando a Teoria do Direito abre-se para um diálogo com a Hermenêutica posterior à virada linguística?

A tentativa de responder estas questões levou à realização de análises que iniciam examinando ou refazendo os caminhos desses saberes (Teoria do Direito e Hermenêutica) no âmbito da produção acadêmica jurídica brasileira, posicionando-os e verificando o que confere legitimidade a um ou a outro discurso. Em seguida, foram analisadas as propostas do neoconstitucionalismo, do pós-positivismo e da nova hermenêutica. Ao final, foram sistematizadas as questões relativas à tarefa hermenêutica em face do positivismo jurídico, suas possibilidades e suas limitações. 


\section{HERMENÊUTICA JURÍDICA: DE SABER PERIFÉRICO AO CENTRO DAS DISCUSSÕES.}

Os manuais de Hermenêutica apontam sua origem nas práticas antigas de adivinhação e antecipação do devir (SOARES, 2010, p. 3). A autoridade de predizer conferia um poder de comando e inspirava o respeito dos outros. A ideia de que o mundo possui um sentido oculto a ser desvelado esteve presente na Antiguidade pagã, no deslumbramento diante do cosmo e do infinito, e se perpetuou na noção de uma palavra divina nas religiões monoteístas, que precisava ser interpretada para que se desvelasse seu sentido oculto. Em todos os casos, tal compreensão imprimia autoridade àqueles que possuíam o saber necessário e suficiente para desvelar o encoberto.

A partir dessa posição inicial, os caminhos tomados no campo hermenêutico moderno podem ser sistematizados em seis direções fundamentais, cronologicamente consideradas: a) uma teoria da exegese bíblica; b) uma metodologia filológica geral; c) uma ciência da compreensão linguística, d) uma base metodológica das ciências do espírito; e) uma fenomenologia da existência e da compreensão existencialmente considerada; e) uma reunião de sistemas interpretativo utilizados para alcançar o significado profundo de mitos e símbolos (PALMER, 1986, p. 43).

Nesse processo delimitou-se uma hermenêutica religiosa, cujo objeto era a palavra divina, e uma hermenêutica filosófica, baseada no desafio da compreensão da palavra humana, não divina. A primeira está envolta na ortodoxia enquanto a segunda tem por fundamento o cogito, a possibilidade de questionar o sentido dos objetos culturais não divinos. A especialização do conhecimento no Renascimento cultural europeu distinguiu saberes ou ciências, permitindo que campos delimitados se desenhassem ao longo dos últimos séculos, trançando um arco que vai da Filosofia do Direito à Teoria do Direito e à Hermenêutica Jurídica, até alcançar o que se denomina Hermenêutica constitucional (PEREIRA, 2007, p.8 e ss).

A virada de maior impacto para a hermenêutica deu-se com o giro hermenêutico, da hermenêutica metodológica de Dilthey à hermenêutica existencial de Heidegger e Gadamer (sécs. XIX e XX), conforme ressalta Streck (2011, p. 231 e ss). Dilthey partia da objetivação como a característica essencial do objeto cultural. Assim, o ato de compreender não era subjetivo. Como todo objeto cultural é inteligível (possui um sentido) e esse sentido é 
objetivo, ele está apto como objeto a ser entendido por uma compreensão comum (partilhada por todos) a qual se chega por um método. Logo, o problema básico da hermenêutica clássica do século XIX é uma questão de método (adequado). A hermenêutica clássica desenvolve os métodos gramatical ou literal, lógico ou sistemático, histórico e teleológico. Afirmava-se que o uso correto do método garantia a correção do resultado final.

$\mathrm{O}$ ingresso no séc. XX determinará a ascensão do Positivismo Jurídico, que se adensava desde John Austin, em meados do sec. XIX. Coube a Kelsen a tarefa de esvaziar o fazer hermenêutico na afirmação da norma como moldura e da decisão como um ato de vontade. Somente o formalismo do Direito poderia ser dado como garantia da validade do resultado final seja do processo de produção da norma, seja da decisão judicial. Este tema voltará a ser desenvolvido no próximo item.

De acordo com Streck (2011), o século XX também produziria a virada linguística, de Ferdinand Saussure a Wittigenstein. Foram Heidegger e Gadamer que se ocuparam de reposicionar a filosofia do ser diante da virada linguística, na afirmação de que o movimento básico da existência humana é compreender. Considerando a Hermenêutica como o saber destinado à atribuição de sentido e a partir da constatação de que todo objeto cultural só terá sentido por ser inteligível, ocorre a desqualificação do pensamento hermenêutico metodológico.

Larenz (1983, p.239 e ss), ao examinar a "jurisprudência” como uma ciência interpretativa, ressalta a estrutura circular do compreender e a importância da pré- compreensão conforme proposta por Gadamer. Segundo Pereira (2007), Gadamer consolidará as noções de pré-compreensão e o círculo ou espiral hermenêutico. O sentido está condicionado a uma précompreensão, preceito definido na máxima de que o texto nada diz a quem não entende já alguma coisa daquilo que ele trata. O Homem possui a capacidade de atribuir sentido ao mundo que o cerca. O sujeito e seu horizonte compreensivo passam a serem os pontos centrais de uma teoria hermenêutica. Gadamer insere historicidade ao sujeito e ao objeto. O efeito de maior impacto nesta postulação é que torna a atividade de compreensão/atribuição de sentido inesgotável, ou seja, constata-se a "inesgotabilidade" do sentido. Gadamer vai buscar na experiência da arte a confirmação de suas assertivas.

No pensamento de Gadamer, fundamentalmente, opera-se a vinculação do sujeito que compreende a história, explicitando a precedência e influência desta em todo conhecimento e em seu próprio ser (OLIVEIRA, 2006, p. 229). Assim, para que o intérprete possa compreender o significado do texto, precisa pensar historicamente, ou seja, realizar uma 
mediação entre os conceitos do passado e o seu pensamento próprio. Deve, portanto, olhar o passado e considerar a concreta situação hermenêutica em que se encontra. Assim, são dois os horizontes significativos: o do texto e o do aplicador.

No caso específico de interpretação do objeto cultural norma jurídica, a amplitude dos horizontes significativos acentua o dever de motivar a decisão. Afirmar que o proceder de interpretar (atribuir sentido) é racional, objetivo e controlável é simultaneamente efeito da constatação dos dois horizontes significativos e consequência do fundamento político do Direito. A transparência do raciocínio atende ao imperativo ético e político de que decisões, em um Estado Democrático de Direito, para se reputarem legítimas, devem convencer de sua adequação àqueles a quem pretenda obrigar. Tem-se, desta forma, evidente a perspectiva integradora da atividade hermenêutica (o legislador ordena e o juiz convence).

O que seja esta atividade de convencimento do julgador ao prolatar sua decisão remete à questão da criação judicial do Direito e aos impasses do positivismo normativista e da proposta da norma como controle da atividade jurisdicional (juízes como os destinatários das normas jurídicas). Esses impasses foram acentuados pelo advento do movimento constitucionalista, no caso brasileiro predominante após o período da redemocratização. Esse cenário revelou-se campo fértil para a adesão à teoria estruturante do Direito de F. Müller (2011, p.291), por meio da qual se passou a entender que a norma não é o texto, mas o resultado de um processo de concretização metodologicamente estruturado: "a norma jurídica torna-se desta forma um conceito complexo composto do âmbito normativo e do programa normativo, isto é, do resultado da interpretação de todos os dados linguísticos". Torna-se imprescindível considerar que, assim como o oráculo, o texto só responde a quem o interroga corretamente, sendo esta a tarefa do hermeneuta. A teoria estruturante do Direito teria sido a responsável por eliminar o hiato existente entre a Teoria do Direito e a Hermenêutica, esvaziada assim desde Kelsen. F. Müller (2011, p. 292) encerra seu livro insistindo que a sua teoria estruturante "é uma teoria da prática” e por isso Müller é perfilado no Brasil ao lado dos pós-positivistas, por superar o positivismo kelseniano que, de acordo com Sousa Filho (2014) ao eliminar a razão prática abandona a prática normativa ao arbítrio e à coerção, subtraindo o direito positivo do âmbito da crítica e da idealidade.

A ciência do Direito, no Brasil, adotou uma perspectiva tripla de análise com Ferraz Júnior. Lançado em 1977, “A Ciência do Direito” (2006) propõe três campos teóricos, ou 
modelos de ciência do Direito: a ciência do Direito como teoria da norma, a ciência do Direito como teoria da interpretação e a ciência do Direito como teoria da decisão. Essa tripla perspectiva, entretanto, teve impacto restrito na formação escolar no Brasil, posto que a ciência do Direito como teoria da norma foi o paradigma para a compreensão da dogmática do Direito pelo menos por mais três décadas. Somente nos anos 90 do século passado a trajetória de ascensão da ciência do Direito como teoria da interpretação foi definida de maneira clara, embora sem referir-se a uma condição científica do Direito. A teoria da decisão ainda está aninhada nas pós-graduações stricto sensu, embora muitas vezes desacompanhada de estudos lógicos que necessariamente a precedem.

Todo esse acumulado teórico gerou uma ansiedade por um novo léxico, por um conjunto vocabular que arejasse e renovasse as teorias da norma e do ordenamento jurídico enquanto "ciência jurídica", revigorando igualmente o modo como se compreende e se pratica o Direito. Novos termos que amparassem, no caso brasileiro, a nova constituição, ou melhor, o texto constitucional compreendido a partir da textura aberta e indeterminada dos preceitos constitucionais. É tempo para os neo, os novos e os pós ${ }^{1}$.

\section{O NEOCONSTITUCIONALISMO, O PÓS-POSITIVISMO E A "NOVA" HERMENÊUTICA}

Os termos neoconstitucionalismo, pós-positivismo e nova hermenêutica ganharam lugar de destaque na formação do bacharel em Direito nos últimos anos, saídos das pósgraduações stricto sensu (Mestrados e Doutorados). Entre nós, a conferência proferida, em 1959, na Alemanha, pelo professor Konrad Hesse, intitulada "A força normativa da constituição", produziu um impacto definitivo. Talvez a força deste impacto tenha desconsiderado a questão constitucional alemã no pós-guerra (ocupação) e o significado decisivo que a interpretação tinha para a consolidação e preservação da força normativa da Lei Fundamental de Bonn, conferindo-lhe a legitimidade faltante no ato constituinte, o que não era o caso da CRFB/88.

\footnotetext{
${ }^{1}$ Em referência ao abundante uso dos termos neo e pós no campo das ciências sociais, posiciona-se Luís Roberto Barroso: “ Sabe-se que veio depois e que tem a pretensão de ser novo. Mas ainda não se sabe bem o que é. Tudo é ainda incerto. Pode ser avanço. Pode ser uma volta ao passado. Pode ser apenas um movimento circular, uma dessas guinadas de 360 graus" (2005, p. 2)
} 
As ideias de Ronald Dworkin e Robert Alexy foram dominando a agenda de pesquisas e a programação de conteúdo das disciplinas de Direito Constitucional, então desdobradas em Constitucional I, II, III... O neoconstitucionalismo, no Brasil, se instalou pelo pensamento, dentre outros, de Luís Roberto Barroso. Definido como o renascimento do Direito Constitucional e caracterizado pelo surgimento de um "sentimento constitucional" no Brasil (lições de Hesse), o marco filosófico desse novo direito constitucional é o póspositivismo. Afirmando a superação histórica do jusnaturalismo e o fracasso político do positivismo, o pós-positivismo busca ir além da legalidade estrita, sem desconsiderar o direito posto: "procura empreender uma leitura moral do Direito, mas sem recorrer a categorias metafísicas" (BARROSO, 2005, p.5). O pós-positivismo se apresenta como superação dialética entre o jusnaturalismo e o juspositivismo, a partir da consideração dos princípios como valores positivados, de acordo com Machado Segundo (2010).

Se o marco filosófico do neoconstitucionalismo é o pós-positivismo, seu marco teórico (as transformações que justificaram uma nova produção de conhecimento no campo do direito constitucional, superando as concepções "convencionais" de aplicação do direito) envolve: a) o reconhecimento da força normativa da constituição; b) a expansão da jurisdição constitucional e c) o desenvolvimento de uma nova dogmática da interpretação constitucional (BARROSO, 2005, p. 5). Clara, em sua formulação, que a teoria do direito passa a ser renovada em suas concepções tradicionais pela teoria do direito constitucional, na qual o campo hermenêutico ocupa o destaque maior, dada a ressignificação do próprio papel e dos limites do Poder Judiciário no Brasil (no sentido de sua expansão) que acompanha as formulações neoconstitucionalistas.

Somente ao final da primeira década do século XXI foram aparecendo os primeiros trabalhos acadêmicos que denunciavam alguns equívocos metodológicos na aplicação das teorias principiológicas (SILVA, 2003) e pugnavam por maior rigor metodológico na atividade do Supremo Tribunal Federal (MARTINS, 2012). Alguns autores passaram a ter uma postura revisionista sobre a questão da liberdade do campo principiológico (NEVES, 2013) e a (in) segurança jurídica no Brasil (GRAU, 2013). O objeto principal deste estudo, entretanto, é verificar a ascensão de uma nova hermenêutica. Por isso ressaltou a importância de dois pensadores que, nesse cenário, contribuíram de maneira decisiva para a consolidação da Hermenêutica no Brasil, destacando especialmente as contribuições de Willis Santiago Guerra e Lênio Streck para consolidar uma interpretação especificamente constitucional. 
Como cenário, politicamente, o Brasil, nos anos 80 do século passado, voltou-se para pensar a transposição de um regime de poder autoritário e centrado no Executivo para um regime de exercício democrático de poder, equilibrado entre Executivo, Legislativo e Judiciário. A questão de qual seria a melhor maneira de se alterar um sistema político desenha algumas possibilidades: via legislativa (que requer uma Constituição sumária e uma intensa atividade legiferante ordinária em seguida), via constituinte (que demanda uma constituição robusta e prolixa) e via judicial (por meio de uma intensa jurisdição constitucional). O Brasil parece ter apostado nos três caminhos.

Qualquer que seja a via escolhida, tem-se duas consequências: a determinação dos novos titulares do poder, ou seja, trata-se de uma escolha não aleatória do ponto de vista político, e o estabelecimento da constituição como lócus hermenêutico. No Brasil, o impacto da vigência de uma nova Constituição fez-se seguir pela interrogação sobre qual a maneira adequada de interpretá-la. A questão da separação entre princípios e regras e da necessária interpretação específica para a espécie normativa princípio abriu espaço para a proporcionalidade e para o sopesamento, inaugurado pelo livro de Guerra Filho, "Ensaios de Teoria Constitucional", publicada ainda em 1989. Os estudos críticos dos anos 80-90 apontavam a ascensão dos direitos “transindividuais" e a (in) capacidade dos juízes brasileiros de tratar judicialmente estas questões, pugnado por um caminho na direção de novos paradigmas, conforme o capítulo 11 da obra "Hermenêutica e(m) crise”, de Lênio Streck, primeira edição no ano 2000.

Diz-se dos princípios que se diferenciam por sua estrutura, uma vez que não há referência a fatos (como na descrição propositiva da norma penal, civil e trabalhista) e nem a consequências de seu não atendimento, por isso tendo alto grau de abstração (GUERRA Filho, 1989). De qualquer forma, os princípios invadem uma esfera conflituosa mal resolvida que é a definição das fontes do Direito, prolongada no disputa entre lei (ordem) e contrato (autonomia das partes). Os princípios também foram definidos como previsão de uma meta e como pressupostos ou postulados de maximização do ordenamento jurídico. De tudo o que foi dito sobre o que sejam os princípios, resta fora de discussão a afirmação da necessidade de uma "nova" hermenêutica.

O objeto dessa nova hermenêutica seriam os princípios constitucionais positivados. Forma e conteúdo dos princípios são problemas hermenêuticos. Os princípios contem uma previsão programática genérica, e a possibilidade permanente de colisão entre princípios requer um princípio harmonizador que impeça a "desfuncionalidade” do sistema jurídico: o princípio 
da proporcionalidade. Assim como, convêm lembrar, a relação entre o Direito e princípios não é nova, a ideia de proporcionalidade no Direito é antiga, confirmada tanto pela filosofia aristotélica como na simbologia do equilíbrio da deusa Diké grega como na Themis romana.

A ausência de uma previsão explícita em nosso texto constitucional de 1988 do princípio da proporcionalidade transformou em tarefa de uma geração específica de juristas o compromisso com a configuração do princípio da proporcionalidade como uma "verdadeira norma jurídica fundamental". O discurso da hipercomplexidade deu aos princípios a tarefa de otimização, voltada a determinar como encontrar as melhores soluções diante da complexidade do mundo moderno. Guerra Filho (2000) ressaltará a dimensão processual da constituição, especialmente pela influência do pensamento de J. Habermas e do agir comunicativo, por meio do qual era possível por opiniões divergentes em comunicação, partindo de um consenso em torno da possibilidade de se chegar a um entendimento mútuo.

No mundo "pós” (pós-moderno, pós-segunda-guerra, pós-positivista) e "híper" (hipercomplexo, hiperespaço), a hermenêutica tem destacado seu caráter pragmático, no qual os métodos tradicionais são necessários, mas não suficientes. A condição de princípios constitucionais como normas superiores requer um novo parâmetro para interpretá-los, uma vez que são, eles próprios, considerados como parâmetros interpretativos para as regras. São realçadas a sua abstração e sua relação com valores. A relação do Direito com a ideia de valores também não é nova: o que é inovador é o reconhecimento de que, em um regime de poder democrático, existe uma insuperável pluralidade de valores, todos com pretensão (legítima ela mesma) de prevalência. Esses valores carreados nos princípios convivem bem na harmonia estática do texto, mas estão em rota permanente de conflito na dinâmica da aplicação.

O tema de conflito entre normas igualmente não é novo. A solução para conflitos de regras é tema explorado na Teoria do Direito, no clássico campo da teoria do ordenamento jurídico. Nos estudos do problema da coerência, as regras explícitas podem se contradisser, provocando as indesejadas antinomias. A solução para as antinomias, depois de identificadas como reais ou aparentes, será a revogação de uma das regras e sua consequente expulsão do ordenamento, sob pena de desqualificá-lo em seu atributo da coerência. É evidente, pelo que foi afirmado acima sobre democracia, que tal solução não de aplicaria sem problemas no caso de colisão entre princípios positivados e implícitos entre si. Afinal, não se pode suprimir um valor que foi constitucionalmente positivado e, portanto, está salvaguardado. 
A hermenêutica constitucional apresenta seus princípios clássicos: unidade da constituição, ou seja, interdependência das normas constitucionais; máxima efetividade da constituição; força normativa da constituição e interpretação conforme a constituição. Guerra Filho (1989) sistematiza os princípios de hermenêutica especificamente constitucional: princípio da proporcionalidade ou harmonização, que se desdobra em adequação, exigibilidade e proporcionalidade em sentido estrito. Dentre outros muitos méritos, a hermenêutica constitucional conforme apresentada por Guerra Filho ressaltou o significado político da interpretação constitucional e sua relação com a teoria dos direitos fundamentais.

A contribuição de Lênio Streck para a hermenêutica constitucional no Brasil também deve ser ressaltada. Tal contribuição está disseminada em obras densas como "Verdade e Consenso" e "Hermenêutica e(m) crise", e também em textos mais descontraídos, como "É possível fazer Direito sem interpretar?” e "A Katchanga e o bullying interpretativo no Brasil”, disponíveis no sítio eletrônico Consultor Jurídico - CONJUR, concorrendo para desmistificar a qualidade de saber hermético e árido, atribuída à atividade hermenêutica. Streck compõe a geração do compromisso constitucional: ao escrever, refirma que o faz por "um sistema judiciário mais democrático, com decisões que contenham um adequado grau de previsibilidade, em que a equanimidade seja o ponto de estofo" (STRECK, 2014, p.32).

Nos escritos de Streck, a estreita relação entre Direito e Literatura remete ao que poderia se designar como uma "macro" hermenêutica, ou à afirmação de partida de que o Direito se equipara ao outros objetos culturais e deve se valer de qualquer ferramenta de atribuição de sentido disponível para o leitor do mundo, inclusive do mundo das normas. Os diálogos de Streck vão de Shakespeare a Jorge Luís Borges, passando por Harold Bloom e Lewis Carrol. Seus escritos ressaltam a relação entre a escrita e a memória, desvelando as marcas da hermenêutica existencialista de Heidegger e Gadamer.

Apenas para citar, relembra-se o uso da peça shakespeariana Medida por medida, no qual o protagonista - o juiz Ângelo, vai de escravo da lei ao senhor do sentido, ressaltando os poderes daquele que se intitula o dono da significação. $O$ poder de atribuir o sentido e a significação de termos como a vida e a sexualidade humana foram objeto de decisões polêmicas e recentes junto ao STF. O exame da fundamentação dos votos dos ministros deixa clara a necessidade do julgador em buscar estas definições em áreas distintas: a biologia apresenta seu discurso sobre o ser vivo, enquanto as ciências sociais, como a sociologia e a antropologia, 
portam seus conceitos sobre o ser vivo homem, numa diversidade de discursos igualmente legítimos.

Questiona-se: até que ponto o Direito e seu compromisso com a decidibilidade conseguem conviver com esta pluralidade de discurso sem entrar em curto-circuito? A sucessão pretendida pelos discursos "neo" e "pós" conseguiram de fato superar o movimento pendular da lei entre o objetivismo e o subjetivismo? Imprimir uma aura de novidade a técnicas e procedimentos supera o dilema da escolha entre a letra da lei e o espírito da lei, tão bem instalado pelo iluminismo de Beccaria? À evidência de que a interpretação não pode se limitar à lei, seguem-se avisos de cautela ao ir além da lei. Determinar o espaço disponível a ser explorado entre os dois extremos parece ser a proposta de uma "nova" hermenêutica, embora remonte à lições de filosofia aristotélica sobre o meio-termo e a temperança.

No compromisso de superar o positivismo exegético, Streck (2014) denuncia o que chama de "ficcionalização" do mundo jurídico-social, ou o império do conceito sem coisas, embora reconheça que seja difícil definir o que é uma discussão meramente sintática. Mas aponta que é no "entremeio das concepções objetivistas e subjetivistas" que encontraremos soluções corretas. A batalha da Hermenêutica contra o decisionismo e a vontade de poder desemboca na teoria da decisão como um controle da atividade judicial (STRECK, 2010, posfácio).

A ideia de controle é uma espécie de contramarcha à batalha travada pelos hermeneutas para evidenciar o papel criativo da hermenêutica em um sistema fundado na vedação de non liquet, com a pretensão de completude do texto jurídico plenipotenciário. Streck (2014) usa a saída da Katchanga "real" para evidenciar o problema: há sempre um não dito, que pode ser tirado da "manga do colete interpretativo". E esse é o papel da interpretação, para o "bem" e para o "mal". Neste último caso, tem-se um efeito danoso do estado de natureza hermenêutico, corrompendo a teoria dos princípios em um panprincipialismo e no que Streck denominou de bullying interpretativo, como se o remédio tivesse se tornado veneno. Mas, quando se está diante desse "mal”, que formas de controle estão disponíveis?

A preocupação com o controle do decisionismo e o reconhecimento da facilidade com que o voluntarismo interpretativo se instalou no Brasil assinala um freio no entusiasmo hermenêutico das últimas décadas. E também denunciam um limite, uma vez que os hermeneutas parecem clamar por uma teoria da decisão ainda por inventar. A hermenêutica parece usar a estratégia do contador de histórias: amanhã eu te conto mais... Tal estratégia é 
lícita ao narrador, mas e ao juiz? É possível finalizar um texto acadêmico com questões e muitos pontos de interrogação, mas não uma sentença.

\section{A DISPOSIÇÃO DO PROBLEMA HERMENÊUTICO}

Três questões finais serão exploradas neste item, formuladas nestes termos: é preciso ultrapassar o positivismo jurídico para adotar a hermenêutica como uma metodologia de aplicação do Direito? Qual a incompatibilidade entre o positivismo e a hermenêutica, compreendida como um conjunto de práticas interpretativas disponíveis para o aplicador do Direito? Que possibilidades são abertas para a Teoria do Direito quando se leva em consideração a reviravolta linguístico-pragmática, colocando a linguagem como condição a priori de todo conhecimento?

A primeira questão atende à ideia de superação do positivismo por "fracasso político". A segunda questão é derivada da afirmação do direito fundamental a uma resposta correta, isto é, adequada à constituição, conforme a teoria do direito como integridade de R. Dworkin. A questão é ainda saber se este critério de correção supera o critério da validade como critério (necessário e suficiente) de aptidão da norma para produzir efeitos e se, superando-o, torna-o dispensável. A terceira, que envolve as duas primeiras, aponta para a necessidade de assumir uma razão dialógica ou comunicacional como condição de possibilidade para qualquer desenvolvimento teórico e prático no campo do Direito.

Pensar sobre o positivismo jurídico é pensar no campo da Teoria do Direito. De acordo com Dimoulis (2006), todas as formas de discurso e argumentação na área jurídica pressupõe a aceitação de uma teoria do direito que possibilite, no mínimo, o próprio uso do termo „direito“ de forma coerente. No mesmo sentido, afirma MacCormick (2006) que uma teoria da argumentação jurídica exige uma teoria do direito e é exigida por esta. Por entender que é um erro identificar os fundamentos da escolha jurisdicional exclusivamente em argumentos dedutivos (positivismo exegético) ou exclusivamente em argumentos não dedutivos (panpricipialismo), Maccormick procura compatibilizar a teoria argumentativa com o positivismo jurídico atualizado ${ }^{2}$. Para MacCormick (2006, p.305), a compreensão do fenômeno jurídico pela teoria juspositivista não autoriza o descarte de discussões sobre valor, princípios, argumentação e interpretação do Direito: 


\begin{abstract}
Não há, porém, nada de antipositivista em dizer que a lei não é isenta de valores. Ninguém em pleno uso das faculdades mentais - e há pelo menos alguns positivistas em pleno uso das faculdades mentais - jamais sugeriu ou sugeriria que a própria lei seja isenta de valores. Se os seres humanos não valorizassem a ordem na vida social, não teriam leis de nenhuma espécie. E cada sistema jurídico encarna não apenas uma forma de ordem social, mas aquela forma de ordem que é especificamente valorizada por quem detém o controle dos processos legislativos, executivo e judiciário - os no mínimo ela é uma colcha de retalhos dos valores rivais preferidos pelos vários grupos que participam desses processos. O sentido de ser positivista não é o de negar verdades óbvias dessa natureza. O sentido consiste, sim, na afirmação de que não se precisa sob nenhum enfoque compartilhar ou endossar esses valores no todo ou em parte para saber que a lei existe ou qual lei existe.
\end{abstract}

Revisitar o positivismo requer uma revisão do que escreveu Kelsen, antes de rever o que se escreveu sobre Kelsen. Comprometido com o rigor metodológico de sua prática teórica, Kelsen (2000, p.636) ocupa-se da validade da ordem jurídica e da autoridade do governo: “de fato, esta doutrina não admite a validade de nenhuma outra ordem jurídica, que não a positiva. (...) Essencialmente, o positivismo se revela apenas ao descartar a ideologia particular que a teoria do Direito usa na sua justificação do Direito positivo". Assim, tem-se o positivismo como: a) uma doutrina que tem como objeto a validade da ordem jurídica positiva, rejeitando a metafísica e buscando a objetividade, e b) uma escola de pensamento comprometida em eliminar o recurso a uma ideologia como meio de legitimação.

\footnotetext{
2 Trata-se de uma obra referenciada no positivismo de H. Hart e, em parte, orientada para refutar o pensamento de R. Dworkin, especialmente aquele constante no "Taking rights seriously". MacCormick utiliza como método o exame de vários casos jurídicos, desde casos mais simples aos mais complexos (bem ao modo sugerido por Hart), examinando o problema de interpretação e construção da argumentação jurídica sediada nas decisões. O processo de aplicar normas possui uma estrutura racional lógica, que pode expressar-se tanto na forma de raciocínio dedutivo como na forma de justificações de segunda ordem, configurados certos fatores. A insistência de MacCormick nessa afirmação mantem sua teoria dentro dos contornos positivistas de respeito ao direito positivo. As justificações de segunda ordem terminam por se constituírem como o ponto mais interessante para o estudioso da argumentação jurídica por é nesse processo de aplicação da norma que se exige um esforço argumentativo mais desenvolvido, mas nem por isso o estudo do Direito pode, ou deve, converter-se em um saber sobre o que é excepcional.
} 
Segundo Dimoulis (2006), o positivismo jurídico constitui um conjunto de proposições técnicas em torno dos seguintes aspectos fundamentais do ordenamento jurídico: definição (fontes, função finalidade), relação com outros fenômenos normativos, interpretação das normas jurídicas e avaliação política e propostas de reforma do direito em vigor. O seu objeto é o direito posto. A consolidação de suas premissas, como já mencionado, se dá em paralelo à monopolização do poder político pelos aparelhos estatais nas sociedades capitalistas, quando ocorre a estatização das fontes do direito. São três, para Dimoulis (2006, p.71), os elementos considerados típicos do juspositivismo: a separação entre direito e moral, a definição do direito como decorrência de mandamentos humanos e sua dependência da autoridade soberana em determinada sociedade. Neste último aspecto desvela-se o ruído com a ideia de uma ordem democrática e a legitimidade da decisão obtida pela justificação da decisão.

Contra o positivismo jurídico está a questão da discricionariedade. Sendo mais específico, contra o positivismo kelseniano e a sua sustentação filosófica, que necessariamente preconiza a separação direito-moral e a cisão entre razão teórica e razão prática. Kelsen não incluía o estudo da decisão no campo da razão teórica. Para o jurista austríaco, não havia como se alcançar o ato decisional ou a passagem da norma à decisão. Por isso o seu corte epistemológico rigoroso e a demarcação de seu objeto de investigação, a norma-texto (embora Kelsen não se refira a ela nestes termos). A decisão judicial fica definida como um ato de vontade e esta discricionariedade abre a possibilidade de muitas respostas (ou qualquer resposta). Trata-se de uma dupla questão de saber e poder e suas implicações recíprocas. Considerada como uma questão de saber, o momento de decidir é uma manifestação da razão prática, fora das possibilidades do conhecimento teórico. Mas considerada uma questão de poder, o ato decisional não pode ficar, sob pena de não ter controle, fora do campo de possibilidades de conhecimento e estudos. A retomada da democracia no Brasil e os "riscos" de uma soberania popular puseram duas questões na pauta: quem é o fiador do Estado de Direito no Brasil e que modelo de Estado constitucional foi instituído.

De toda forma, antes de prosseguir, é preciso retomar uma questão que insiste em aparecer: o desafio de entender a relação Direito e Moral, esta última bem instalada no campo da razão prática. O pós-positivismo parecer trazer uma reaproximação inevitável entre Direito e Moral, com a possibilidade de controle da atividade judicial por meio de um apelo a esta última, denunciando o fracasso do positivismo que se negava a ver as questões morais implicadas no ato de decidir. Convém lembrar que outro positivista, H. Hart (2012), reconheceu 
a importância das questões morais no ato de obediência às normas, ou seja, o Direito dependia de um mínimo da moral para resolver a questão de porque obedecemos às normas. Assim, da escola exegética francesa ao positivismo e ao pós-positivismo há um longo caminho. Os defensores do positivismo exegético, no qual texto e norma estão colados (Direito=Lei), foram produtos de um necessário e contextualizado conflito entre a afirmação poder do Estado e os outros centros irradiadores de poder (como a Igreja e as corporações de ofícios medievais). O positivismo pós-exegético afirmou a discricionariedade judicial em função do reconhecimento do limite do conhecimento. O pós-positivismo e o retorno triunfal da Hermenêutica buscam superar esse limite. Convém lembrar que Kelsen (1994) não via na hermenêutica essa propriedade (atributo).

De fato, compreende-se que Kelsen foi um "purista”, mas não deixou de apontar as questões políticas como definidoras do Direito. A questão Direito e Política está presente em toda a vasta produção kelseniana, seja nos escritos sobre Democracia seja nos estudos sobre o Estado; assim como MacCormick (2006), discípulo de Hart, reafirma a necessidade de consultar a relação Direito-Política, mais do que a relação Direito-Moral.

A questão que se põe é como a Hermenêutica pretende superar o limite reconhecido pelo positivismo de controle do ato de decidir. O problema da validade se desloca da norma para a validade da interpretação e, portanto, da decisão. Como foi visto, o fazer hermenêutico é a chave disposta na teoria estruturante do Direito de F. Müller, ou seja, a hermenêutica seria o meio ou a metodologia para fazer a passagem controlada do texto à norma.

Assim, interpretar é, acima de tudo, explicitar o que se compreende. Para Motta (2012), Dworkin, por reconhecer a impossibilidade de os juízes se livrarem da razão prática (eivada de solipsismos) "ataca" esse problema a partir da responsabilidade política de cada juiz/intérprete/aplicador, obrigando-o (has a duty to) a obedecer à integridade do Direito, ou o contínuo narrativo do fazer o Direito, evitando que as decisões se baseiem em raciocínios ad hoc (teleológicos, morais ou de política). A hermenêutica converte-se numa tentativa de blindagem da discricionariedade judicial. Assim, a validade da decisão é o resultado de determinados processos de argumentação em que se confrontam razões e se reconhece a autoridade de um argumento. Portanto, a hermenêutica é posta em rota de colisão com o protagonismo e a discricionariedade.

O problema hermenêutico se instala diante do protagonismo judicial em um Estado que assume uma constituição dirigente, gerando assim um novo modelo de processo civil em função 
de uma concepção de Estado. A Hermenêutica se estabelece como o campo, simultaneamente, de construção de condições de possibilidade para a concretização de direitos e de interdição de relativismos interpretativos, evitando a discricionariedade judicial e a possível arbitrariedade judicial. Essa dupla função da Hermenêutica, de acordo com Motta (2012), abre duas perspectivas. A perspectiva substancialista, que demanda em Dworkin a reaproximação entre Direito e Moral, e a perspectiva processualista, que impõe a garantia constitucional da fundamentação da decisão e a exigência hermenêutica de fundamentação dessas decisões. Convém somente lembrar que a perspectiva substancialista e a leitura moral da constituição (pela qual se compreende que a constituição traz o ideal moral transformado em obrigação jurídica) e o papel dos princípios miravam os direitos (rigths) e não uma compreensão do que seja o Direito (Law) enquanto objeto de estudos.

Diante dessa constatação, é salutar questionar o que é um direito, fazendo-o na perspectiva de verificar qual a intenção de um Estado de sustentar os direitos anunciados em sua constituição. É esse o aviso contido no taking rights seriously de Ronald Dworkin? É necessário questionar se o Direito como um instrumento de transformação da sociedade está posto na CRFB/88. Se de uma leitura especificamente liberal ou especificamente progressista resultar respostas diferentes e opostas, o problema ainda não está resolvido.

A perspectiva procedimentalista põe outras questões, como: quando o problema da interpretação se instala como um problema jurídico? Para o todos são iguais perante a lei, desafio posto pelo iluminismo do séc. XVIII, surgem as diferentes interpretações, abrindo espaço para o casuísmo? A tese da única resposta correta de Dworkin foi levada a sério no Brasil pós-88? Como evitar que a interpretação se converta numa espécie de linha de fuga da aplicação da lei?

Para iluminar essa discussão, faz-se necessário colocar a última questão, qual seja, a abertura da Teoria do Direito para a virada linguístico-pragmática operada na filosofia do século XX. Ao tomar a linguagem como centro da reflexão filosófica, considerando-a não mais um instrumento de expressão do pensamento, mas como a própria condição do pensamento, sendo portanto constitutiva de qualquer experiência humana de sentido, profundos efeitos na concepção de subjetividade e racionalidade são atingidos. Assim, o modelo kantiano de subjetividade, concebido fora da temporalidade e da história, é reconstruído segundo o paradigma da intersubjetividade, em que o homem é "desde o nascimento, um ser em comunicação com outros seres, um ser temporal e espacialmente condicionado [...]. É preciso 
reconhecer não só a relação eu-mundo, mas a relação entre as subjetividades, a relação eu-outro como condicionantes do processo de conhecimento" (CAMPOS; ALBUQUERQUE, 2015, p. 777). É a intersubjetividade como constitutiva e indispensável da razão, o que a define como razão discursiva ou comunicativa.

É este novo paradigma de racionalidade discursiva que representa uma abertura do Direito para outras construções teóricas, e que torna possível recompor um diálogo com a tradição positivista antes que se decrete o seu "fracasso político", no sentido de reconstruir acordos de sentido em torno do que já foi considerado parâmetro evidente, objetivo e unívoco para a interpretação e hoje precisa passar pelo exercício da fundamentação segundo a razão comunicativa. Constitui também um contraponto ao voluntarismo aberto pelas concepções neoconstitucionalistas, que abusam do principiologismo e da frágil técnica da ponderação como fórmulas mágicas para produzir decisões que não podem encontrar amparo senão no exercício arbitrário do poder político de interpretar. Mesmo abandonada a ideia de um sentido unívoco a que se pode acessar com um método, não se perde a condição de que direito segue parâmetros de racionalidade. E sendo a razão intersubjetiva, todos os processos interpretativos devem se dar em interação discursiva, segundo "uma organização em procedimento fundada na ideia de comunicação inclusiva” (CAMPOS; ALBUQUERQUE, 2015, p. 778)

O fato é que se pode afirmar com segurança que produzir uma decisão a partir de uma norma de referência (inferência) é um jogo de equilíbrio entre termos gerais e precisão de conteúdo. As teorias da linguagem desvelaram a condição de vagueza e ambiguidade das palavras, mas também afirmaram a indisponibilidade da linguagem, sob pena de um desacordo total, que inviabilizaria a convivência coletiva. Nos estudos linguísticos, ambiguidade e vagueza passam a ser considerados atributos não acidentais, mas próprios das palavras. Desde Habermas, interpretar torna-se a atividade de selecionar possibilidades comunicativas da complexidade discursiva, considerando que a linguagem somente existe em função dos acordos sobre significados que, uma vez constituídos, reduzem o espaço de disponibilidade do intérprete. Quanto o Judiciário é visto como o dono da significação, o primeiro impedimento para sua atividade é o poder transcendental da linguagem, e nisso a Hermenêutica parece ser unânime.

Por fim, cite-se a perspectiva hermenêutica que afirma que cada processo de interpretação envolve uma modificação do entendimento de normas previamente estabelecidas, dentro de uma esfera de discricionariedade do juiz. Segundo Barak (2006, p. 
257), discricionariedade é "o poder que tem o juiz para escolher entre várias interpretações alternativas, cada uma delas igualmente legal: não há interpretação sem discricionariedade" 3 . Conciliar esta compreensão com o fato de que igualmente não se pode afirmar uma visão ceticista da norma (que autorize a afirmação de que leis e jurisprudência são em todas as circunstâncias tão indeterminadas ao ponto de não impor absolutamente nenhum limite às possíveis faixas de interpretação ou explicação) parece ser o desafio posto para hermeneutas e teóricos do Direito.

\section{CONSIDERAÇÕES FINAIS}

Muitos questionamentos foram se colocando ao longo da escrita deste trabalho. A tentativa de construir questionamentos é também uma contribuição para o debate acadêmico, mesmo que fiquem abertos, apenas postos. Ainda assim, ariscam-se algumas respostas. $\mathrm{O}$ movimento de centralidade da Hermenêutica jurídica nos debates acadêmicos não deve ser entendido como um ocaso da Teoria do Direito, mas antes como uma aplicação de campos de estudos. O objeto de estudos desses saberes se complementam. A Teoria do Direito não se reduz ao positivismo jurídico e, embora isso pudesse ser cogitado, pode-se afirmar que o positivismo ainda não esgotou suas possibilidades teóricas, até mesmo considerando que a proposta do póspositivismo o tem como ponto de referência. Não é preciso ultrapassar o positivismo jurídico para adotar a hermenêutica como "metodologia" do Direito, mas antes promover uma releitura do positivismo e renová-lo como proposta teórica sob uma perspectiva política, assim como o discurso hermenêutico trouxe novos aportes, a partir da virada linguística e do giro hermenêutico existencialista, que justificam o entusiasmo inovador que invade e legitima este campo de estudos.

Um positivismo que aceite a prática interpretativa como um meio de controle da discricionariedade judicial degenerada em arbitrariedade, sem se configurar, entretanto, como uma linha de fuga da legalidade democrática. A introdução da expressão "Democrático" na fórmula "Estado de Direito", conforme dispõe a CRFB/88, não autoriza o descarte, por "superação", do paradigma da validade no Direito, mas consolida mais um critério de verificação da aptidão do Direito para produzir efeitos (a legitimidade), ao lado do critério da validade de norma jurídica e legalidade da decisão judicial.

\footnotetext{
3 "Judicial discretion is the power of the judge to choose among several interpretative alternatives, each of which is lawful. The can be no interpretation without discretion". BARAK, 2006, p.257.
} 
O saber jurídico não pode recusar a condição do Direito na modernidade ser um sistema de referência para as condutas e para a solução de conflitos. Por tratar-se de uma questão de poder, o fazer do Direito deve ser minimamente controlado. Toda atividade que recorre a um método é controlável e limitada (pelo método). O problema de aplicar a lei e construir a decisão enquanto discurso, isto é, estratégia que envolve convencimento e acatamento de uma ordem, é que a sujeição ao controle sempre encontra resistência dos que exercem um poder.

Se, ao indagar-se o que é a ciência jurídica, afinal, se puder responder que é um saber sobre a norma jurídica, considerada como um imperativo normativo em função da autoridade de quem a enuncia (o Estado), então será de pouca utilidade uma teoria da decisão, a partir da necessidade de convencimento. Mas se por ciência jurídica se puder entender um saber sobre a construção de uma decisão controlável segundo mecanismos fundados na racionalidade comunicativa, então a convergência de saberes teóricos e hermenêuticos será uma grande conquista.

Se prática do Direito é interpretativa e não se cindem os momentos de compreensãointerpretação-aplicação, somente se compreende e se interpreta aplicando. E se não há momentos distintos, como deve o juiz construir sua decisão entre o compreender, o interpretar e o aplicar? Parecem ser estes os limites da afirmação de que a Hermenêutica ou a Teoria do Direito possam isoladamente construir respostas para a complexa tarefa de decidir e justificar a decisão. Entre a Hermenêutica e a Teoria do Direito, parece que as fichas de apostas estão em um "novo" campo, uma "nova" disciplina que ainda não se instalou, por sua vez, na formação dos profissionais do Direito no Brasil.

\section{REFERÊNCIAS BIBLIOGRÁFICAS}

BARAK, Aharon. The judge in a Democracy. Princeton University Press, 2006.

BARROSO, Luís Roberto. Neoconstitucionalismo e constitucionalização do Direito (O triunfo tardio do direito constitucional no Brasil). 2005. Disponível em: < http://www.luisrobertobarroso.com.br/wpcontent/themes/LRB/pdf/neoconstitucionalismo_e_constitucionalizacao_do_direito_pt.pdf> Acesso em 16.07.2015.

CAMPOS, Juliana Cristine Diniz; ALBUQUERQUE, Felipe Braga. Nova Hermenêutica Constitucional e (in)segurança jurídica: características e críticas da virada linguística no interpretar da Constituição. Revista Quaestio Iuris. Rio de Janeiro, v. 08, n. 02, pp. 774-792, 2015. 
DIMOULIS, Dimitri. Positivismo Jurídico: introdução a uma teoria do direito e defesa do pragmatismo jurídico-político. São Paulo: Método, 2006.

FERRAZ JÚNIOR, Tércio Sampaio. A Ciência do Direito. 2 ed., 14. reimpr. São Paulo: Atlas, 2006.

GRAU, Eros Roberto. Porque tenho medo dos juízes - a interpretação/aplicação do direito e dos princípios. 6 ed. ref. São Paulo: Malheiros, 2013.

GUERRA FILHO, Willis Santiago. Ensaios de Teoria Constitucional. Fortaleza: Imprensa Universitária-UFC, 1989.

Teoria Processual da Constituição. São Paulo: Celso Basto Editor- Instituto Brasileiro de Direito Constitucional, 2000.

HART, Herbert L. A.. O conceito de direito. 1 ed 2 tir. São Paulo: Editora WMF Martins Fontes, 2012.

KELSEN, Hans. Teoria Pura do Direito. 4. ed. São Paulo: Martins Fontes, 1994.

Teoria do Direito e do Estado. 3 ed., 2 tir.. São Paulo: Martins Fontes, 2000.

LARENZ, Karl. Metodologia da Ciência do Direito. Trad. José Lamego. 5. ed. rev. Lisboa: Fundação Calouste Gulbenkian, 1983.

MacCORMICK, Neil. Argumentação jurídica e teoria do direito. São Paulo: Martins Fontes, 2006.

MACHADO SEGUNDO, Hugo de Brito. Fundamentos do Direito. São Paulo: Atlas, 2010.

MARTINS, Leonardo. Liberdade e Estado Constitucional: leitura jurídico-dogmática de uma complexa relação a partir da teoria liberal dos direitos fundamentais. São Paulo: Atlas, 2012.

MOTTA, Francisco José Borges. Levando o Direito à sério. 2. ed. Porto Alegre: Livraria do Advogado, 2012.

MÜLLER, Friedrich. Teoria Estruturante do Direito. Trad. Peter Neumann e Eurides Avance de Sousa. 3. ed. rev. atual. São Paulo: Revista dos Tribunais, 2011.

NEVES, Marcelo. Entre Hidra e Hércules: princípios e regras constitucionais como diferença paradoxal do sistema jurídico. São Paulo: WMF Martins Fontes, 2013.

OLIVEIRA, Manfredo Araújo de. Reviravolta linguístico-pragmática na filosofia contemporânea. São Paulo: Loyola, 2006.

PALMER, Richard. Hermenêutica. Trad. Maria Luísa Ribeiro Ferreira. Lisboa: Edições 70, 1986.

PEREIRA, Rodolfo Viana. Hermenêutica Filosófica e Constitucional. 2 ed. Belo Horizonte: Del Rey, 2007.

SILVA, Virgílio Afonso. Princípios e regras: mitos e equívocos acerca de uma distinção. Revista Latino Americana de Estudos constitucionais. Belo Horizonte: Del Rey, n.1 jan/jul. 2003.

SOUSA FILHO, José Ivan Rodrigues. A intolerável tolerância de Hans Kelsen: as contradições performáticas do purismo jurídico. In: Filosofia do Direito I [Recurso eletrônico online] organização CONPEDI/UFSC; coordenadores: Prof. Dr. José Alcebíades de Oliveira 
Júnior (UFRGS), Prof. Dr. Róbson Tramontina (UNOESC), Prof. Dr. André Leonardo Copetti Santos (URI). Florianópolis: CONPEDI, 2014. Disponível em: <http://www.publicadireito.com.br/artigos/?cod=77e86f5489a21d22 >. Acesso em 21.jul.2015.

SOARES, Ricardo Maurício Freire. Hermenêutica e interpretação jurídica. São Paulo: Saraiva, 2010.

STRECK, Lênio Luiz. Hermenêutica jurídica e(m) crise: uma exploração hermenêutica da construção do Direito. 10.ed.rev.,atual. e ampl. Porto Alegre: Livraria do Advogado, 2011.

Compreender Direito: desvelando as obviedades do discurso jurídico. 2.ed. São Paulo: Editora Revista dos Tribunais, 2014. V.1. 